\title{
Article \\ Conceptual Design Evaluation Considering Confidence Based on Z-AHP-TOPSIS Method
}

\author{
Qinghua Liu ${ }^{1}(0)$ Jiadui Chen ${ }^{1, *}$, Weixing Wang ${ }^{2}{ }^{\oplus}$ and Qing Qin $^{2}$ \\ 1 Key Laboratory of Advanced Manufacturing Technology, Ministry of Education, Guizhou University, \\ Guiyang 550025, China; yazawaninico@163.com \\ 2 College of Mechanical Engineering, Guizhou University, Guiyang 550025, China; wwx515@sina.com (W.W.); \\ qinqing0506@163.com (Q.Q.) \\ * Correspondence: jdchen1@gzu.edu.cn
}

Citation: Liu, Q.; Chen, J.; Wang, W.; Qin, Q. Conceptual Design Evaluation Considering Confidence Based on Z-AHP-TOPSIS Method. Appl. Sci. 2021, 11, 7400. https:// doi.org/10.3390/app11167400

Academic Editor: Enrico Vezzetti

Received: 11 July 2021

Accepted: 10 August 2021

Published: 12 August 2021

Publisher's Note: MDPI stays neutral with regard to jurisdictional claims in published maps and institutional affiliations.

Copyright: (c) 2021 by the authors. Licensee MDPI, Basel, Switzerland. This article is an open access article distributed under the terms and conditions of the Creative Commons Attribution (CC BY) license (https:/ / creativecommons.org/licenses/by/ $4.0 /)$.

\begin{abstract}
In concept design, effective decision making and management of schemes can shorten the design cycle and improve product quality. The decision maker (DM)'s confidence is one of the critical factors affecting the conceptual design evaluation. Although many studies use quantitative linguistic evaluation for design scheme decision-making, which improves product conceptual design decision-making efficiency and effectiveness, few studies consider the confidence level of a decision. A conceptual design evaluation method based on Z-numbers is proposed to solve this problem, considering the customer requirements and the DM's confidence. Firstly, the evaluation criteria are determined by analyzing customer requirements; then, the fuzzy analytic hierarchy process in the Z-numbers environment (Z-AHP) is used to determine the criteria weight; Finally, the fuzzy technique for order preference by similarity to ideal solution method in the Z-numbers environment (Z-TOPSIS) is used to evaluate the design schemes to obtain the optimal scheme. The proposed method is applied to the selection of the design scheme of the waste containers in the kitchen. The results show that considering the DM's self-confidence can achieve a more reasonable and practical evaluation of the conceptual design scheme, and it is easier to obtain the best scheme.
\end{abstract}

Keywords: conceptual design evaluation; Z-numbers; fuzzy AHP; fuzzy TOPSIS; confidence

\section{Introduction}

With the continuous improvement of living standards and industrialization levels, people put forward higher and higher requirements for product diversification, personalization, and upgrading, making the product cycle shorter and shorter and leading to more and more fierce market competition. Only the product that meets the customer's requirements can make the enterprise win the market competition. In the new product development stage, the decision in the conceptual design is particularly significant, and it impacts all subsequent stages and the cost, quality, and performance of the final product [1]. Hence, the conceptual design evaluation, which determines the best design among alternatives, is the most critical part of product development because a reasonable conceptual design evaluation can avoid moving a flawed concept to the subsequent design process and avoid losing a feasible concept [2]. Although conceptual design evaluation is critical, it is a difficult task because there is only a rough idea in the conceptual design stage, and the current information is almost incomplete, fuzzy, or inaccurate. As a result, it cannot be easy to make the right choice. Due to the lack of information, decisions at this stage significantly impact the ongoing design process, as shown in Figure 1 [3]. As shown in Figure 1, the impact of design decisions is very high at first and decreases sharply as the design matures (i.e., when there is greater availability of information). There are great opportunities in the preliminary design stage. The concepts generated in this stage affect the essential shape generation and material selection of relevant products. The area before the intersection of the two curves is an opportunity for conceptual design. In the subsequent detailed 
design stage, this area will become smaller and may become irreparable or correctable in the product design stage.

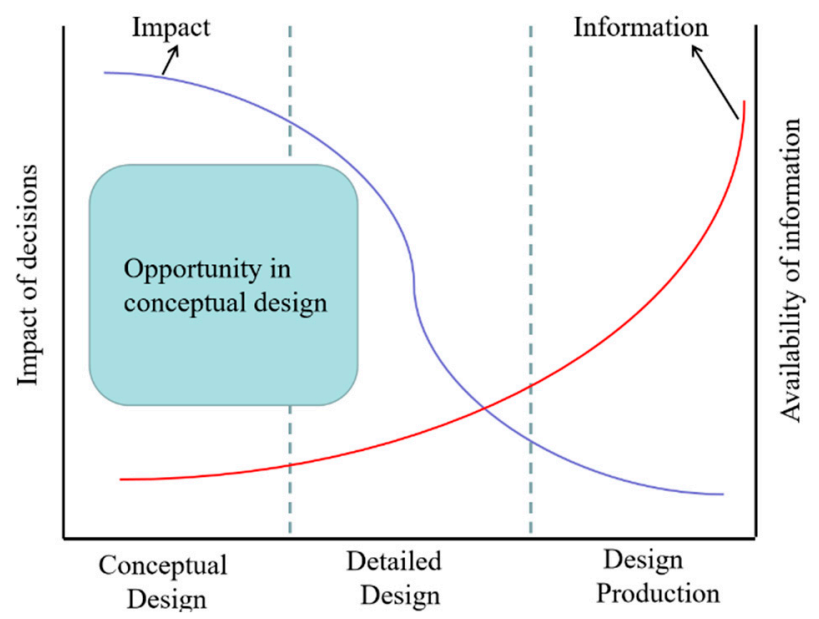

Figure 1. Opportunity in conceptual design.

In conceptual design evaluation, decision-makers (DMs) prefer to use natural language to express judgment and preference with the increase of reference factors or evaluation indicators. For example, define an evaluation scale set as (good, poor, very poor) to evaluate the practicability of a product. In this case, the linguistic terms in the evaluation scale set are linguistic variables [4]. The traditional scoring method maps linguistic variables to a precise value (such as good $=2$, very poor $=0$ ) to quantify linguistic terms, which is classical logic (also known as binary logic or Boolean logic) [5]. However, in the evaluation process, semantic concepts are often uncertain, and whether an element belongs to a semantic concept is often a gradual process rather than a mutation process. For example, if the concept with a score of more than five is defined as "good" then "good" is classical logic, and the score of 5 is "good" while 4.9 is not "good". Its set representation is shown in Figure 2a. In fact, in people's understanding there is no big difference between 5 and 4.9 (more than five belongs to "good", but 4.9 also belongs to "good").

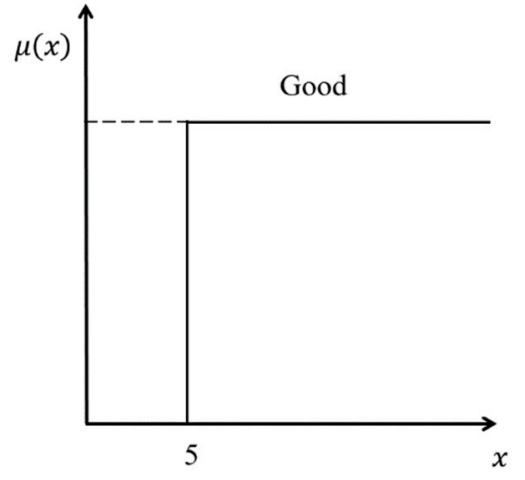

(a)

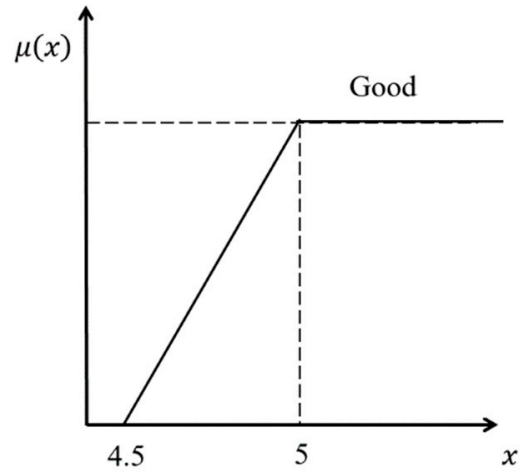

(b)

Figure 2. Different representations of "good". (a) Classical set (b) Fuzzy set.

In order to better model semantic concepts, Zadeh [6] proposed fuzzy set theory. It extends the representation of classical sets and expresses the membership degree of each element in the set as [0,1], which is usually used to describe the value of linguistic variables. Using fuzzy sets can grasp the inherent fuzziness of human evaluation better, more accurately, and more meaningfully. Figure $2 \mathrm{~b}$ is a fuzzy set corresponding to the semantic concept of "good". The scores between 4.5 and 5 are also "good", but they have different degrees of membership. Compared with classical logic, fuzzy sets can better 
model the uncertainty of people's understanding of semantic concepts. Therefore, the fuzzy linguistic quantification method is a very suitable method of modelling and processing the relevant information of conceptual design evaluation [7]. To formalize the uncertainty, Zadeh proposed the Z-number method [8]. Z-number is an ordered pair $(A, B)$, where $A$ is a fuzzy value and $B$ is $A^{\prime}$ 's reliability. Since $Z$-number describes both the limit of value and the reliability of the limit, it describes human knowledge more comprehensively than general fuzzy numbers. When the influence of uncertainty is significant, the uncertainty can be accurately modeled by using a Z-number.

The traditional method of conceptual design evaluation is to think that the information is reliable or definite. However, knowledge or information in the real world contains various types of uncertainty. When the reliability of information is ignored, we need to consider the potential information loss and its impact. According to the literature [9], there are two main types of information imperfection: uncertainty and imprecision. Due to the influence of professional background, knowledge level, experience, and other factors, DM will produce different degrees of hesitation and uncertainty in different evaluation indexes. This phenomenon is accessible to causes deviation in scheme evaluation and may not obtain the product design scheme to meet the market demand and enterprise profit demand. At present, the research of conceptual design evaluation focuses on combining the existing decision-making methods and adding fuzzy methods to improve the authenticity of evaluation information, mainly using a fuzzy set, rough number, or rough set evaluation without considering the reliability of decision-making related information (that is, the degree of hesitation and uncertainty of DM) [10,11]. If we do not consider DM's confidence in the evaluation index, the evaluation may be too subjective, or the result may be unreasonable.

Given the above problems, we propose different DMs to use different evaluation confidence scales for conceptual design evaluation to make up for the lack of quantitative information reliability when using the fuzzy method. When the available information is qualitative, fuzzy sets are used to model semantics in conceptual design evaluation. Then, a Z-number is used to supplement these fuzzy sets with additional fuzzy sets, representing the reliability of the previous fuzzy set, that is, the certainty of DM for information evaluation. First, DM evaluates the concept and shows the degree of selfconfidence. Constructing and using different confidence linguistic term sets to express the situation from self-confidence to non-self-confidence can reflect the knowledge level and experience differences of different DMs. Then, the Z-number is used to represent the evaluation information of DMs, and it is transformed into a regular fuzzy number. Next, fuzzy AHP in the Z-number environment (Z-AHP) is used to determine the weight of customer requirements. Finally, fuzzy TOPSIS in the Z-number environment (Z-TOPSIS) is used to sort the design schemes.

The rest of this paper is structured as follows. The second section summarizes the literature on concept selection methods. Section 3 introduces some basic concepts and methods. The fourth section is a case study that proves the proposed framework's feasibility through a new design task. The fifth section is the discussion and the sixth section is the conclusion.

\section{Literature Review}

Due to the increasing diversification of consumer demand in new product development (NPD), enterprises want to obtain products that meet the expected results and need to adopt modern methods, technologies, and tools to reduce production costs [12]. As conceptual design evaluation plays an essential role in NPD, it has attracted the attention of many researchers $[13,14]$. Conceptual design evaluation is the process of determining design criteria and selecting the best scheme from the possible options, which can be considered a multi-attribute decision-making (MADM) problem. MADM deals with finding the best solution from a limited number of solutions, which usually have the characteristics of large number and conflict. With the increase in the number of alternatives available for 
evaluation and the decrease in available time, it is difficult for DMs to make the objective decision because of the imprecise information regarding alternatives. Some related studies consider statistical methods to complete the new design conceptual evaluation such as SWOT (strength/weakness/opportunity/threat) analysis [15], Pugh matrix [16], balanced scorecard [17], etc. Although the statistical evaluation method is simple and suitable for applications, its evaluation efficiency is significantly reduced for complex NPD. Another more general evaluation method is to utilize various MADM models, such as the analytic hierarchical process (AHP) [18], the analytic network process (ANP) [19], the technique for order preference by similarity to ideal solution (TOPSIS) [20], and weighted aggregated sum product assessment (WASPAS) [21], have been utilized to evaluate design options and select the best design concept. In addition, the application of the stochastic multicriteria acceptability analysis (SMAA) in MADM also achieved good results [22,23].

The above methods are deterministic models. Because DMs are faced with fuzzy information in the early stage of product design, they prefer to use natural language for evaluation. The deterministic model cannot fully capture the fuzzy and subjective judgment and preference in the design evaluation process. The fuzzy set theory effectively solves these problems and has been applied in many fields. Yan et al. [24] proposed a novel adaptive mask generating algorithm based on the fuzzy set theory to automatically calculate an optimal threshold. Jasiulewicz-Kaczmarek et al. [25] presented a new method based the fuzzy set theory to measure the level of maintenance sustainability.

Therefore, it is beneficial to combine the deterministic method with the fuzzy evaluation method. For instance, Shaverdi et al. [26] proposed a framework of financial performance evaluation based on fuzzy TOPSIS. Abdel-Baset et al. [27] proposed the fuzzy ANP method using fuzzy triangular numbers to represent linguistic variables and calculated the critical metrics of significant and export cities. Goswami et al. [28] proposed a hybrid fuzzy model for evaluation to converge upon product design concepts associated with lesser supply chain risks.

When the subjective judgment of DM is transformed into a fuzzy number, there may be potential problems because the confidence of DMs, that is, the information about how sure the DM is of the evaluation, is not included in this transformation. Unlike the classical fuzzy set theory, once the Z-number is used, DM can add the reliability related to judgment into decision-making to eliminate ambiguity and enhance the objectivity of evaluation information. The successful application of Z-number in MADM also appears in the literature. Onari et al. [29] proposed a method based on a multilevel fuzzy cognitive map and Z-number theory to evaluate the risk of the production process by considering both reliability and uncertainty. Alireza Ghahtarani [30] proposed a mathematical model of the portfolio problem based on Z-number and gave the best portfolio in all deterministic and non-deterministic formulas under bubble conditions. Shen et al. [31] extended the classical vlsekriterijum-ska optimizacija i kompromisno resenje (VIKOR) method to the Z-information environment and proposed the Z-VIKOR method based on a distance measure. Hendiani et al. [32] presented the application of the Z-number for modeling the earned value indicators and explicated the capability of the Z-number in dealing with higher levels of uncertainty associated with decision-making data. Wang et al. [33] introduced linguistic Z-numbers (LZNs) and proposed a comparison method based on the score and accuracy functions of LZNs. Peng et al. [34] introduced hesitant uncertain linguistic Z-numbers (HULZNs) to depict uncertain decision-making information. Ren et al. [35] proposed a method based on hesitant fuzzy linguistic information for medicine selection. Although there are many MADM methods based on Z-numbers, there are few studies on applying Z-numbers to conceptual design evaluation, and it is necessary to include uncertainty in conceptual design evaluation.

In this study, we obtain the subjective judgment and preference of DM and add the degree of self-confidence to the conceptual design evaluation. By comprehensively modeling the uncertainty in decision-making, we try to avoid deviation or even bad 
decision-making caused by DM professional background, knowledge level, experience, and other factors.

\section{Materials and Methods}

\subsection{Fuzzy Linguistic Approach}

The process of representing linguistic variables as a set of fuzzy sets is called fuzzy quantization. DMs can express the inherent fuzziness of evaluation more accurately and more expressively by using fuzzy numbers compared with real numbers.

\subsubsection{Fuzzy Set}

$A$ fuzzy set is described by a membership function mapping the elements of a universe $X$ to the unit interval $[0,1]$ and is defined below [6]:

$$
A: X \rightarrow[0,1]
$$

It can also be described as a set of ordered pairs of the form:

$$
A=\left\{\left(x, \mu_{A}(x) \mid \forall \in X, \mu_{A}(x) \in[0,1]\right)\right\},
$$

where $x$ is an element of $X$ and $\mu_{A}(x)$ denotes its corresponding degree.

In conceptual design evaluation, information about incomplete evaluation is often expressed as the fuzzy number in a normal fuzzy set [36]. In many fuzzy number representations, trapezoidal fuzzy number (TpFN) and triangular fuzzy number (TFN) are often used because they are easy to calculate [37].

$\operatorname{A~TpFN~}(a, b, c, d)$ is defined as follows:

$$
\mu(x)=\left\{\begin{array}{l}
0, x<a \\
\frac{x-a}{b-a}, a \leq x \leq b \\
1, b \leq x \leq c \\
\frac{d-x}{d-c}, c \leq x \leq d \\
0, x>d
\end{array}\right.
$$

A TFN $(a, b, c)$ is defined as follows:

$$
\mu(x)=\left\{\begin{array}{l}
0, x<a \\
\frac{x-a}{b-a}, a \leq x \leq b \\
\frac{c-x}{c-b}, b \leq x \leq c \\
0, x>c
\end{array},\right.
$$

\subsubsection{Z-Number}

A Z-number $(A, B)$ is an ordered pair of fuzzy numbers, where $A$ indicates a fuzzy restriction on the values domain $X$ can take, and $B$ represents a reliability measure of $A$. The advantage of the Z-number comes from the consideration of the confidence level of the value of the related variables. For instance, a Z-number $((3,5,7),(0.5,0.75,1,1))$ shows that the value of variable $(A)$ is defined by " $(3,5,7)$ " TFN and the associated reliability $(B)$ is described with the " $(0.5,0.75,1,1)$ " TpFN.

\subsection{The Method of Converting Z-Number to Regular Fuzzy Number}

Assume a Z-number $Z=(A, B)$. Let $A=\left\{\left(x, \mu_{A}(x) \mid \forall \in X, \mu_{A}(x) \in[0,1]\right)\right\}$ and $B=\left\{\left(x, \mu_{B}(x) \mid \forall \in X, \mu_{B}(x) \in[0,1]\right)\right\}$. The steps to convert $Z$ to a regular fuzzy number are as follows [32]:

Step 1. Turn the second part (reliability) of the Z-number into a crisp number.

$$
\alpha=\frac{\int x \mu_{B}(x) d x}{\int \mu_{B}(x) d x}
$$


where $\int$ denotes an algebraic integration.

Step 2. Add the weight of the second part (reliability) to the first part (restriction).

The weighted Z-number can be denoted as:

$$
\widetilde{Z}^{\alpha}=\left\{\left\langle x, \mu_{A^{\alpha}}(x)\right\rangle \mid \mu_{A^{\alpha}}(x)=\alpha \mu_{A}(x), x \in[0,1]\right\},
$$

Equation (6) can be simplified as shown in Equation (7), representing the Z-number after multiplying the reliability:

$$
\widetilde{Z}^{\alpha}=(A ; \alpha),
$$

Step 3. Convert the irregular fuzzy number (weighted restriction) to a regular fuzzy number.

Since Equation (7) is still not in the form of the standard fuzzy number, a conversion operation is required.

The regular fuzzy number can be denoted as:

$$
\widetilde{Z}^{\prime}=\left\{\left\langle x, \mu_{\widetilde{Z}^{\prime}}(x)\right\rangle \mid \mu_{\widetilde{Z}^{\prime}}(x)=\mu_{A^{\alpha}}\left(\frac{x}{\sqrt{\alpha}}\right), x \in[0,1]\right\},
$$

Equation (8) can be denoted by Figure 3.

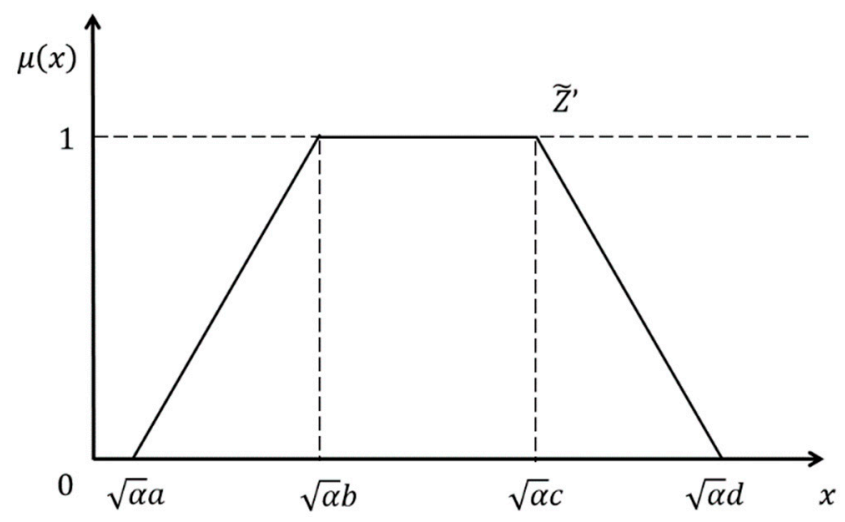

Figure 3. The regular fuzzy number transformed from Z-number.

A numerical example is used to illustrate the procedure of this approach. Assume a DM gives his opinion as good $(3,5,7)$ TFN and his confidence is absolutely $(0.5,0.75,1,1)$ TpFN, the DM's knowledge can be expressed with a Z-number as: $Z$ = (good, absolutely) $=((3,5,7),(0.5,0.75,1,1))$. At first, we should convert the DM's reliability into a crisp number according to Step 1 .

$$
\alpha=\frac{\int x \mu_{B}(x) d x}{\int \mu_{B}(x) d x}=0.8056
$$

Second, add the weight of reliability to the constraint:

$$
\widetilde{Z}^{\alpha}=((3,5,7) ; 0.8056)
$$

Third, convert the weighted Z-number to a regular fuzzy number:

$$
\widetilde{Z}^{\prime}=((\sqrt{0.8056} \times 3, \sqrt{0.8056} \times 5, \sqrt{0.8056} \times 7) ; 1)=(2.6926,4.4876,6.2827)
$$

Then, calculate (good, weak), where "weak" is assigned $(0,0,0.25,0.5) \mathrm{TpFN}$. By converting $\mathrm{Z}=$ (good, absolutely) and $\mathrm{Z}=$ (good, absolutely) into regular fuzzy numbers and drawing their corresponding membership function images, Figure 4 can be obtained. The linguistic term that means "good" is assigned $(3,5,7)$ TFN, "good, weak" is assigned $(1.3329,2.2046,3$. 0867) TFN and "good, absolutely" is assigned $(2.6926,4.4876,6.2826)$ TFN 
over the total range of $[1,9]$. It can be seen from Figure 4 that even the same evaluation will lead to a deviation due to different confidence levels, which will have a specific impact on decision making.

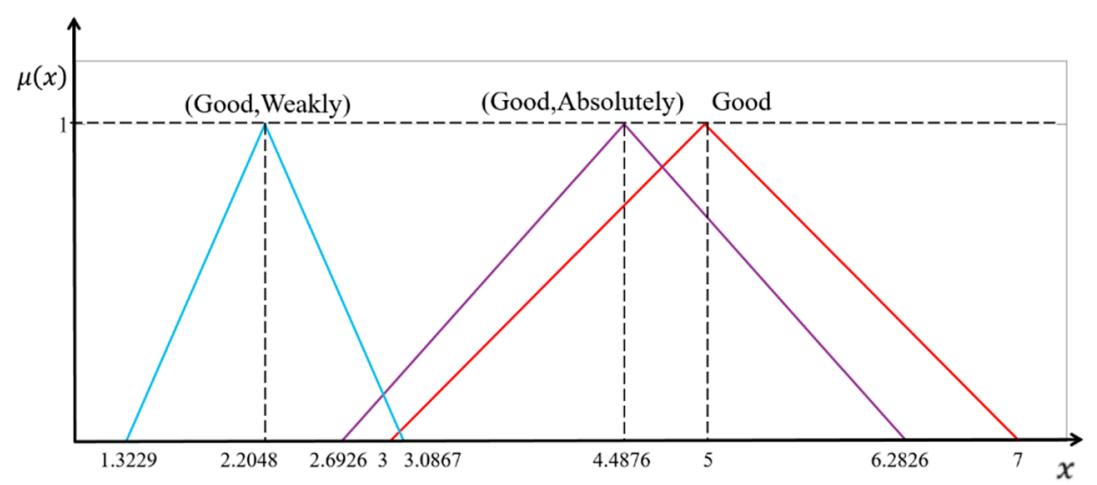

Figure 4. TFN of "good" corresponding to different confidence levels.

\subsection{Z-AHP}

When DMs utilize fuzzy AHP [38] to calculate the weight of criteria, the linguistic terms are expressed as $(L, M, U)$ TFNs. Assuming that there are $n$ criteria, the matrix $P$ is used for pairwise comparison of criteria by DMs as follows:

$$
\begin{gathered}
P=\left(P_{i j}\right)=\left(L_{i j}, M_{i j}, U_{i j}\right)= \\
(1,1,1) \\
{\left[\begin{array}{cccc}
\left(L_{12}, M_{12}, U_{12}\right) & \cdots & \left(L_{1 n}, M_{1 n}, U_{1 n}\right) \\
\left(1 / U_{12}, 1 / M_{12}, 1 / L_{12}\right) & (1,1,1) & \cdots & \left(L_{2 n}, M_{2 n}, U_{2 n}\right) \\
\vdots & \vdots & \vdots & \vdots \\
\left(1 / U_{1 n}, 1 / M_{1 n}, 1 / L_{1 n}\right) & \left(1 / U_{2 n}, 1 / M_{2 n}, 1 / L_{2 n}\right) & \cdots & (1,1,1)
\end{array}\right],}
\end{gathered}
$$

where the symmetric fuzzy number of the main diagonal is $P_{i j}=P_{i j}^{-1}=\left(1 / U_{i j}, 1 / M_{i j}, 1 / L_{i j}\right)$.

This paper uses the Chang algorithm [39] and improves it based on Z-number as follows:

Step 1. Build pairwise comparison matrix with linguistic terms.

DMs utilize $Z=(A, B)$ to compare the indicators, $A$ is the evaluation value, $B$ is the confidence, so the pairwise matrix can be expressed as:

$$
\begin{gathered}
P=\left(P_{i j}\right)=\left(\left(L_{i j}^{A}, M_{i j}^{A}, U_{i j}^{A}\right),\left(L_{i j}^{B}, M_{i j}^{B}, U_{i j}^{B}\right)\right)= \\
{\left[\begin{array}{cccc}
(1,1,1) & \left(\left(L_{12}^{A}, M_{12}^{A}, U_{12}^{A}\right),\left(L_{12}^{B}, M_{12}^{B}, U_{12}^{B}\right)\right) & \cdots & \left(\left(L_{1 n}^{A}, M_{1 n}^{A}, U_{1 n}^{A}\right),\left(L_{1 n}^{B}, M_{1 n}^{B}, U_{1 n}^{B}\right)\right) \\
- & (1,1,1) & \cdots & \left(\left(L_{2 n}^{A}, M_{2 n}^{A}, U_{2 n}^{A}\right),\left(L_{2 n}^{B}, M_{2 n}^{B}, U_{2 n}^{B}\right)\right) \\
\vdots & \vdots & \vdots & \vdots \\
- & - & \cdots & (1,1,1)
\end{array}\right],}
\end{gathered}
$$

where the symmetric elements of the main diagonal are temporarily vacated, and the main diagonal elements are $(1,1,1)$.

Step 2. Transform the Z-numbers into regular fuzzy numbers and supplement the elements of the diagonal symmetric position.

By using the method proposed in Section 3.2, the Z-numbers in the pairwise comparison matrix is transformed into regular fuzzy numbers, and then the symmetric elements of the main diagonal are supplemented to obtain the following matrix: 


$$
\left[\begin{array}{cccc}
P=\left(P_{i j}\right)= & \\
(1,1,1) & \left(\widetilde{L_{12}}, \widetilde{M_{12}}, \widetilde{U_{12}}\right) & \cdots & \left(\widetilde{L_{1 n}}, \widetilde{M_{1 n}}, \widetilde{U_{1 n}}\right) \\
\left(1 / \widetilde{U_{12}}, 1 / \widetilde{M_{12}}, 1 / \widetilde{L_{12}}\right) & (1,1,1) & \ldots & \left(\widetilde{L_{2 n}}, \widetilde{M_{2 n}}, \widetilde{U_{2 n}}\right. \\
\vdots & \vdots & \vdots & \vdots \\
\left(1 / \widetilde{U_{1 n}}, 1 / \widetilde{M_{1 n}}, 1 / \widetilde{L_{1 n}}\right) & \left(1 / \widetilde{U_{2 n}}, 1 / \widetilde{M_{2 n}}, 1 / \widetilde{L_{2 n}}\right) & \cdots & (1,1,1)
\end{array}\right],
$$

Step 3. Calculate the extension of the fuzzy synthesis.

The extension of the fuzzy synthesis $S_{i}$ is calculated for the $i$-th criterion by the following formula:

$$
S_{i}=\sum_{j=1}^{n} P_{i j} \otimes\left\{\sum_{i=1}^{n} \sum_{j=1}^{n} P_{i j}\right\}^{-1} ; i=1,2, \ldots, n .,
$$

Step 4. Calculate the degree of possibility.

The degree possibility for a convex fuzzy number to be greater than $i$ convex fuzzy numbers $V_{j}$ can be defined by Equation (13) [39].

$$
V\left(S_{j} \geq S_{i}\right)=\left\{\begin{array}{c}
1, \text { if } \widetilde{M}_{j} \geq \widetilde{M}_{i}, i=1,2, \ldots, n ; j=1,2, \ldots, n . \\
\frac{\widetilde{L_{i}}-{\widetilde{U_{j}}}}{\left(\widetilde{M}_{j}-\widetilde{U}_{j}\right)-\left(\widetilde{M}_{i}-\widetilde{L}_{i}\right)}, \text { if } \widetilde{U_{j}} \geq \widetilde{L_{i}}, i=1,2, \ldots, n ; j=1,2, \ldots, n . \\
0, \text { in other cases }
\end{array}\right.
$$

The theory of the comparison of the fuzzy numbers is applied to the comparison of the values.

$$
V_{j}=V\left(S_{j} \geq S_{1}, S_{2}, \ldots, S_{j-1}, S_{j+1}, \ldots, S_{n}\right)=\min \left\{V\left(S_{j} \geq S_{i}\right), i=1, \ldots, n ; i \neq j\right\},
$$

Step 5. Calculate normalized weight of criteria $w_{j}$.

$$
w_{j}=\frac{V_{j}}{\sum_{j=1}^{n} V_{j}}, j=1,2, \ldots, n .,
$$

\subsection{Z-TOPSIS}

Z-TOPSIS is an improvement based on the traditional fuzzy TOPSIS [40]. The specific steps are as follows:

Step 1. Build a decision matrix with linguistic terms.

Assume that there are $m$ schemes and $n$ criterion in the conceptual design, the DMs use $\mathrm{Z}$-number $\mathrm{Z}=(A, B)$ to make decisions, so the decision matrix is as follows:

$$
M=\left[Z_{i j}\right]=\left[\begin{array}{ccc}
\left(A_{11}, B_{11}\right) & \cdots & \left(A_{1 n}, B_{1 n}\right) \\
\vdots & \ddots & \vdots \\
\left(A_{m 1}, B_{m 1}\right) & \cdots & \left(A_{m n}, B_{m n}\right)
\end{array}\right]_{m \times n},
$$

The Z-AHP weight $w$ is added to the decision matrix, as shown below:

$$
M=\left[Z_{i j}\right]=\left[\begin{array}{ccc}
w_{1}\left(A_{11}, B_{11}\right) & \cdots & w_{n}\left(A_{1 n}, B_{1 n}\right) \\
\vdots & \ddots & \vdots \\
w_{1}\left(A_{m 1}, B_{m 1}\right) & \cdots & w_{n}\left(A_{m n}, B_{m n}\right)
\end{array}\right]_{m \times n},
$$

Step 2. Transform the Z-numbers into regular fuzzy numbers. 
Through Section 3.2, the Z-numbers in the evaluation matrix are transformed into regular fuzzy numbers as follows:

$$
M=\left[Z_{i j}\right]=\left[\begin{array}{ccc}
\widetilde{Z}_{11}^{\prime} & \cdots & \widetilde{Z}_{1 n}^{\prime} \\
\vdots & \ddots & \vdots \\
\widetilde{Z}_{m 1}^{\prime} & \cdots & \widetilde{Z}_{m n}^{\prime}
\end{array}\right]_{m \times n},
$$

Step 3. Identify the positive ideal solution (PIS) and negative ideal solution (NIS).

PIS and NIS can be calculated as:

$$
\begin{aligned}
& I^{+}=\left\{\left(\max \widetilde{Z}_{i j}^{\prime} \mid i=1,2, \ldots, m\right)\right\}=\left\{\widetilde{Z}_{1}^{\prime+}, \widetilde{Z}_{2}^{\prime+}, \ldots, \widetilde{Z}_{n}^{\prime+}\right\}, \\
& I^{-}=\left\{\left(\min \widetilde{Z}_{i j}^{\prime} \mid i=1,2, \ldots, m\right)\right\}=\left\{\widetilde{Z}_{1}^{\prime-}, \widetilde{Z}_{2}^{\prime-}, \ldots, \widetilde{Z}_{n}^{\prime-}\right\},
\end{aligned}
$$

where $I^{+}$and $I^{-}$denote PIS and NIS, respectively.

Step 4. Calculate the distances between criterion and both PIS and NIS.

Define $d$ as the gap between two fuzzy numbers. When given two TFNs, F1 $\left(L_{1}, M_{1}, U_{1}\right)$ and F2 $\left(L_{2}, M_{2}, U_{2}\right), d$ can be calculated by Equation (21):

$$
d=\sqrt{\frac{1}{3}\left[\left(L_{1}-L_{2}\right)^{2}+\left(M_{1}-M_{2}\right)^{2}+\left(U_{1}-U_{2}\right)^{2}\right]},
$$

Then, calculate the distance of each alternative from $I^{+}\left(d_{i}^{+}\right)$and $I^{-}\left(d_{i}^{-}\right)$, respectively.

$$
\begin{aligned}
& d_{i}^{+}=\sum_{j=1}^{n} d\left(\widetilde{Z}_{i j}^{\prime}, I_{j}^{+}\right), i=1,2, \ldots, m ., \\
& d_{i}^{-}=\sum_{j=1}^{n} d\left(\widetilde{Z}_{i j}^{\prime}, I_{j}^{-}\right), i=1,2, \ldots, m .,
\end{aligned}
$$

Step 5. Calculate the closeness degrees and obtain the ranking orders.

The closeness degree $C_{i}$ can be calculated by Equation (24) and the optimal scheme with the maximum closeness:

$$
C_{i}=\frac{d_{i}^{-}}{d_{i}^{+}+d_{i}^{-}}
$$

\subsection{The Framework of the Proposed Method}

At present, the self-confidence of DM is rarely considered in conceptual design evaluation methods. However, there is always hesitation and uncertainty in DM's evaluation. If the self-confidence of the evaluators is not considered in the conceptual design evaluation, the result may be unreasonable, and even the worst design scheme may become the winning scheme. This paper proposes a decision-making framework of the product design scheme, as shown in Figure 5. The process of conceptual design evaluation is as follows: Firstly, DMs (DM1, DM2, ... , DMs) determine the criteria after complete discussion by combining the factors such as product design history, process, user preference, or market. Then, the DMs determine the confidence scale (confidence scale $1, \ldots$, confidence scale s) through each person's professional knowledge or experience. Next, the DMs determine the criterion weight of each design scheme by the Z-AHP. Finally, the Z-TOPSIS is used to rank all the evaluation schemes to obtain the ranking results. 


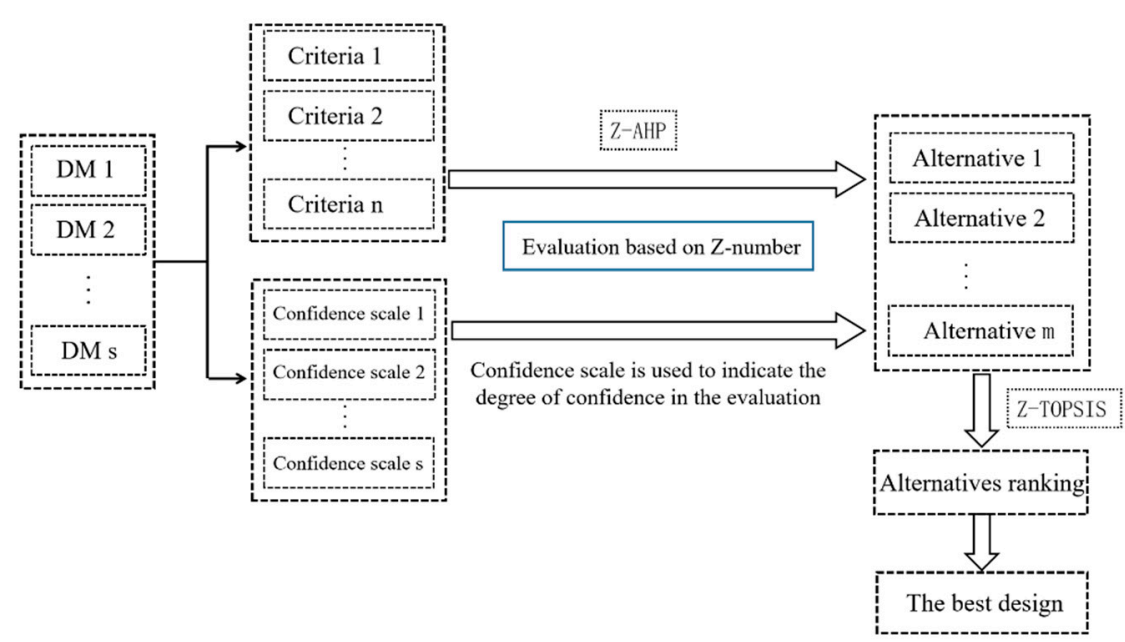

Figure 5. The proposed conceptual design evaluation framework.

\section{Results}

In this section, the concept design evaluation method considering self-confidence is applied to an innovative design task, and its feasibility is analyzed and compared with the existing methods.

With the development of the economy and improvements in people's living standards, people's requirements for the kitchen and its supporting furniture and facilities are also higher and higher. The kitchen is a place to ensure people's healthy diet, but the design of the waste container in the kitchen is often ignored. We study the recycling and treatment of kitchen waste to realize the conceptual design of the waste container.

The specific process is as follows:

Step 1. Identification of customer requirements and evaluation of linguistic terms.

Initially, investigate the customers to understand the problems and functions of their current waste containers. A questionnaire and field investigation is adopted, and a decision-making group composed of designers and managers is set up for the project. After complete discussion by the decision-making group, the following customer requirements are determined, as shown in Table 1:

Table 1. Customer requirements.

\begin{tabular}{cc}
\hline Criterion & Customer Requirements \\
\hline$C_{1}$ & Relative capacity \\
$C_{2}$ & Multi-function \\
$C_{3}$ & Convenience \\
$C_{4}$ & Service life \\
$C_{5}$ & Cost \\
\hline
\end{tabular}

The psychological research shows that, due to the limited short-term memory ability, human beings can reasonably remember $7 \pm 2$ items, so it is relatively safe to use up to 5 items in the fuzzy set [41]. Then, the fuzzy number is used to establish the corresponding linguistic terms to avoid directly assigning equidistant values [42]. We determine the appropriate membership function for each criterion to improve the accuracy of the results and optimize the uncertainty of the evaluation criteria, as shown in Figure 6.

In Figure 6, the linguistic term that means the design is "poor" is assigned $(1,1,3)$ TFN. By analogy, "fair" is assigned $(1,3,5)$ TFN, "good" is assigned $(3,5,7)$ TFN, and "excellent" is assigned $(7,7,9)$ TFN over the total range of $[1,9]$. However, the professional background, knowledge level, and experience of DMs are not the same, so it is inevitable that there will be different confidence in the evaluation index when evaluating the scheme. The designer, in this case, has a high degree of self-confidence, which is reflected in the 
number of self-confidence scales. Therefore, the self-confidence scale used is three, which means that the degree of hesitation in evaluation is low, as shown in Figure 7.



Figure 6. Evaluation of linguistic terms.

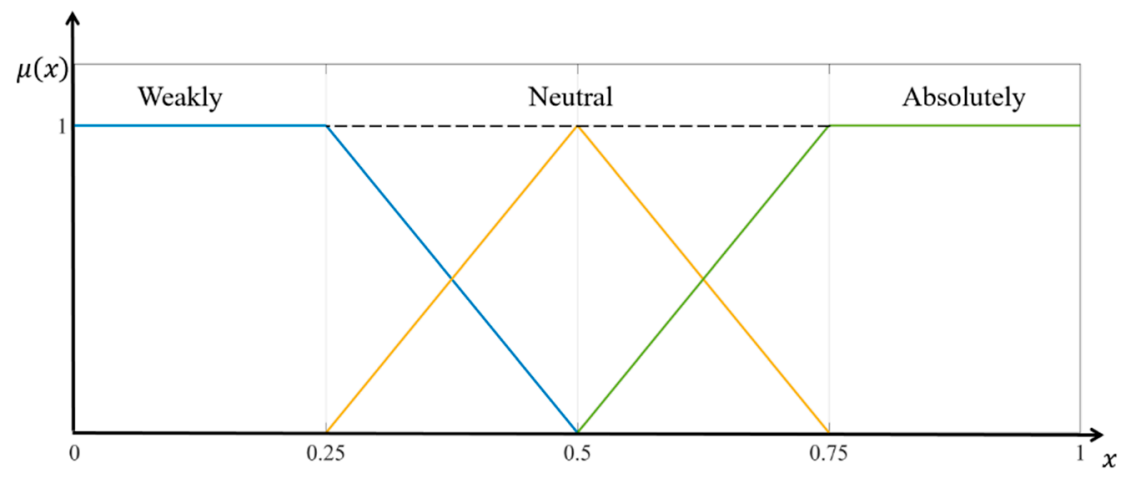

Figure 7. Three-scale self-confidence linguistic terms.

The linguistic term that means the confidence in evaluation is "weak" is assigned $(0,0,0.25,0.5) \mathrm{TpFN}$, "neutral" is assigned $(0.25,0.5,0.75) \mathrm{TFN}$, and "absolutely" is assigned $(0.5,0.75,1,1) \mathrm{TpFN}$ over the total range of $[0,1]$.

Step 2. Determination of criterion weight.

Designers use the fuzzy AHP method in the Z-numbers environment to determine the weight of customer requirements. The steps are as follows:

Step 2.1. Develop a paired comparison matrix for customer requirement.

The designer made a pairwise comparison of the factors, and the results are shown in Table 2.

Table 2. The fuzzy comparison matrix for the defined criteria.

\begin{tabular}{cccccc}
\hline Criterion & $C_{1}$ & $C_{2}$ & $C_{3}$ & $C_{4}$ & $C_{5}$ \\
\hline$C_{1}$ & $(1,1,1)$ & $(\mathrm{G}, \mathrm{N})$ & $(\mathrm{E}, \mathrm{W})$ & $(\mathrm{V}, \mathrm{A})$ & $(\mathrm{F}, \mathrm{N})$ \\
$C_{2}$ & - & $(1,1,1)$ & $(\mathrm{F}, \mathrm{N})$ & $(\mathrm{F}, \mathrm{A})$ & $(\mathrm{G}, \mathrm{N})$ \\
$C_{3}$ & - & - & $(1,1,1)$ & $(\mathrm{P}, \mathrm{W})$ & $(\mathrm{P}, \mathrm{A})$ \\
$C_{4}$ & - & - & - & $(1,1,1)$ & $(\mathrm{P}, \mathrm{A})$ \\
$C_{5}$ & - & - & - & - & $(1,1,1)$ \\
\hline
\end{tabular}

P: Poor; F: Fair; G: Good; V: Very good; E: Excellent; W: Weak; N: Neutral; A: Absolutely.

Step 2.2. Transform the Z-numbers into regular fuzzy numbers, and supplement elements about the diagonal symmetric position.

The complete fuzzy comparison matrix obtained from Section 3.3 is shown in Table 3: 
Table 3. The complete fuzzy comparison matrix for the defined criteria.

\begin{tabular}{cccccc}
\hline Criterion & $C_{\mathbf{1}}$ & $C_{\mathbf{2}}$ & $C_{\mathbf{3}}$ & $C_{\mathbf{4}}$ & $C_{\mathbf{5}}$ \\
\hline$C_{1}$ & $(1,1,1)$ & $(2.12,3.54,4.95)$ & $(3.09,3.97,3.97)$ & $(4.48,6.28,8.08)$ & $(0.71,2.12,3.54)$ \\
$C_{2}$ & $(0.20,0.28,0.47)$ & $(1,1,1)$ & $(0.71,2.12,3.54)$ & $(0.87,2.60,4.33)$ & $(2.12,3.54,4.95)$ \\
$C_{3}$ & $(0.25,0.25,0.32)$ & $(0.28,0.47,1.41)$ & $(1,1,1)$ & $(0.5,0.5,1.5)$ & $(0.87,0.87,2.60)$ \\
$C_{4}$ & $(0.12,0.16,0.22)$ & $(0.23,0.38,1.15)$ & $(0.67,2.0,2.0)$ & $(1,1,1)$ & $(0.87,0.87,2.60)$ \\
$C_{5}$ & $(0.28,0.47,1.41)$ & $(0.20,0.28,0.47)$ & $(0.39,1.15,1.15)$ & $(0.39,1.15,1.15)$ & $(1,1,1)$ \\
\hline
\end{tabular}

Step 2.3. Calculate the weights of every criterion.

By means of Equations (12)-(14), $S_{i}$ of criterion can be calculated as follows:

$$
\begin{gathered}
S_{1}=(11.40,16.91,21.53) \odot\left(\frac{1}{23.34}, \frac{1}{38.01}, \frac{1}{54.83}\right)=(0.21,0.45,0.89) \\
S_{2}=(4.90,9.54,14.29) \odot\left(\frac{1}{23.34}, \frac{1}{38.01}, \frac{1}{54.83}\right)=(0.09,0.25,0.59) \\
S_{3}=(2.90,3.09,6.84) \odot\left(\frac{1}{23.34}, \frac{1}{38.01}, \frac{1}{54.83}\right)=(0.05,0.08,0.28) \\
S_{4}=(2.89,4.41,6.98) \odot\left(\frac{1}{23.34}, \frac{1}{38.01}, \frac{1}{54.83}\right)=(0.05,0.12,0.29) \\
S_{5}=(2.26,4.06,5.20) \odot\left(\frac{1}{23.34}, \frac{1}{38.01}, \frac{1}{54.83}\right)=(0.04,0.11,0.29)
\end{gathered}
$$

$V_{j}$ of criterion can be calculated as follows:

$$
\begin{gathered}
V_{1}=\min \left\{V\left(S_{1} \geq S_{2}, S_{3}, S_{4}, S_{5}\right)\right\}=\min \{1,1,1,1\}=1 \\
V_{2}=\min \left\{V\left(S_{2} \geq S_{1}, S_{3}, S_{4}, S_{5}\right)\right\}=\min \{0.66,1,1,1\}=0.66 \\
V_{3}=\min \left\{V\left(S_{3} \geq S_{1}, S_{2}, S_{4}, S_{5}\right)\right\}=\min \{0.17,0.53,0.87,0.9\}=0.17 \\
V_{4}=\min \left\{V\left(S_{4} \geq S_{1}, S_{2}, S_{3}, S_{5}\right)\right\}=\min \{0.19,0.59,1,1\}=0.19 \\
V_{5}=\min \left\{V\left(S_{5} \geq S_{1}, S_{2}, S_{3}, S_{4}\right)\right\}=\min \{0.02,0.46,1,0.95\}=0.02
\end{gathered}
$$

Step 2.4. Calculate normalized weight of criteria.

By means of Equation (15), the normalized weight vector is $w=\{0.49,0.32,0.08,0.09,0.007\}$.

Step 3. Generation of the design possibilities.

Through the analysis of customer requirements and the analysis of existing waste containers in the kitchen, four conceptual designs are obtained using the conceptual design method proposed in reference [43], as shown in Figure 8. Design 1 adopts dry wet separation, and an outlet is added at the bottom to discharge wastewater, as shown in Figure 8a. Design 2 uses a rotatable storage box instead of the traditional container cover, and wheels are added at the bottom to facilitate movement, as shown in Figure 8b. Design 3 adds a fixed broom and a side opening based on the traditional container, as shown in Figure 8c. Design 4, shown in Figure 8d, uses a rotatable polygon structure to realize garbage classification. However, each design has some advantages and disadvantages, so the applicability is still uncertain.

Step 4. Selection of the best design.

Hereafter, Z-TOPSIS is applied to identify the applicability of the design possibility concerning customer satisfaction.

Step 4.1. Generation of decision matrix.

Here, the decision matrix would be a $(4 \times 5)$ matrix with four design possibilities (alternatives) and five customer requirements (criteria), as shown in Table 4. 


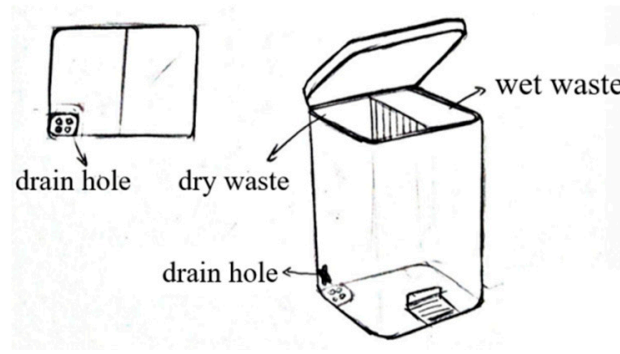

(a)

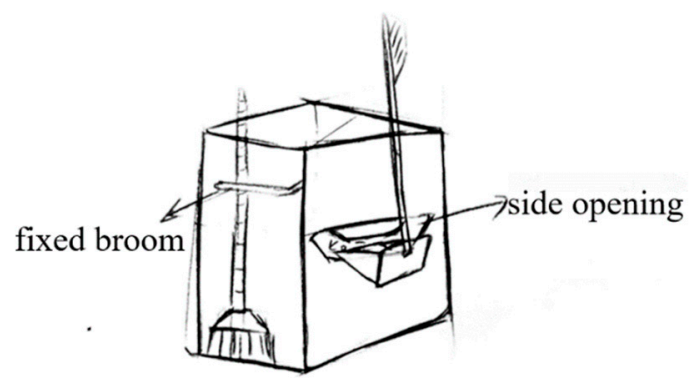

(c)

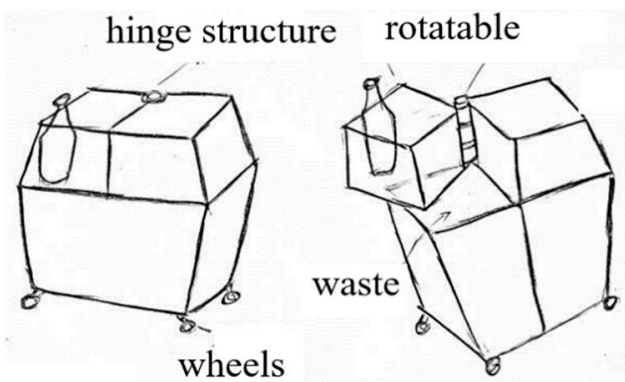

(b)

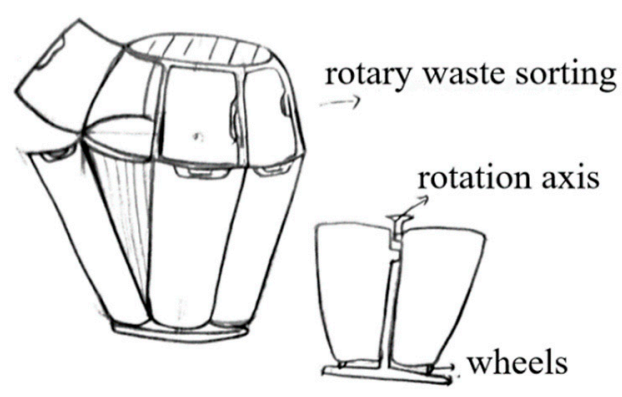

(d)

Figure 8. Conceptual design of four kinds of waste containers in the kitchen. (a) Design 1 (b) Design 2 (c) Design 3 (d) Design 4 .

Table 4. Decision matrix.

\begin{tabular}{cccccc}
\hline Criterion $\rightarrow$ & $C_{\mathbf{1}}$ & $\boldsymbol{C}_{\mathbf{2}}$ & $C_{\mathbf{3}}$ & $C_{\mathbf{4}}$ & $C_{\mathbf{5}}$ \\
Alternative $\downarrow$ & $\boldsymbol{w}_{\mathbf{1}}=\mathbf{0 . 4 9}$ & $\boldsymbol{w}_{\mathbf{2}}=\mathbf{0 . 3 2}$ & $\boldsymbol{w}_{\mathbf{3}}=\mathbf{0 . 0 8}$ & $\boldsymbol{w}_{\mathbf{4}}=\mathbf{0 . 0 9}$ & $\boldsymbol{w}_{\mathbf{5}}=\mathbf{0 . 0 0 7}$ \\
\hline Design 1 & $(\mathrm{P}, \mathrm{W})$ & $(\mathrm{F}, \mathrm{N})$ & $(\mathrm{G}, \mathrm{A})$ & $(\mathrm{G}, \mathrm{A})$ & $(\mathrm{G}, \mathrm{A})$ \\
Design 2 & $(\mathrm{E}, \mathrm{A})$ & $(\mathrm{V}, \mathrm{A})$ & $(\mathrm{F}, \mathrm{A})$ & $(\mathrm{E}, \mathrm{A})$ & $(\mathrm{P}, \mathrm{A})$ \\
Design 3 & $(\mathrm{F}, \mathrm{W})$ & $(\mathrm{F}, \mathrm{W})$ & $(\mathrm{V}, \mathrm{N})$ & $(\mathrm{F}, \mathrm{W})$ & $(\mathrm{G}, \mathrm{W})$ \\
Design 4 & $(\mathrm{P}, \mathrm{N})$ & $(\mathrm{G}, \mathrm{N})$ & $(\mathrm{V}, \mathrm{A})$ & $(\mathrm{V}, \mathrm{A})$ & $(\mathrm{V}, \mathrm{A})$ \\
\hline P: Poor; F: Fair;
\end{tabular}

P: Poor; F: Fair; G: Good; V: Very good; E: Excellent; W: Weak; N: Neutral; A: Absolutely.

Step 4.2. Weighting and transformation of Z-numbers.

By the means of Equations (17) and (18), the Z-AHP weighted decision matrix is as shown in Table 5.

Table 5. Z-AHP weighted decision matrix.

\begin{tabular}{cccccc}
\hline Criterion $\rightarrow$ & $C_{\mathbf{1}}$ & $C_{\mathbf{2}}$ & $C_{\mathbf{3}}$ & $\boldsymbol{C}_{\mathbf{4}}$ & $C_{\mathbf{5}}$ \\
Alternative $\downarrow$ & $\boldsymbol{w}_{\mathbf{1}}=\mathbf{0 . 4 9}$ & $\boldsymbol{w}_{\mathbf{2}}=\mathbf{0 . 3 2}$ & $\boldsymbol{w}_{\mathbf{3}}=\mathbf{0 . 0 8}$ & $\boldsymbol{w}_{\mathbf{4}}=\mathbf{0 . 0 9}$ & $\boldsymbol{w}_{\mathbf{5}}=\mathbf{0 . 0 0 7}$ \\
\hline Design 1 & $(0.25,0.25,0.74)$ & $(0.23,0.69,1.15)$ & $(0.21,0.36,0.50)$ & $(0.25,0.41,0.57)$ & $(0.02,0.034,0.047)$ \\
Design 2 & $(2.98,3.83,3.83)$ & $(1.41,1.97,2.53)$ & $(0.07,0.21,0.36)$ & $(0.57,0.74,0.74)$ & $(0.007,0.007,0.02)$ \\
Design 3 & $(0.25,0.74,1.23)$ & $(0.16,0.49,0.81)$ & $(0.29,0.41,0.52)$ & $(0.05,0.14,0.24)$ & $(0.012,0.019,0.027)$ \\
Design 4 & $(0.35,0.35,1.04)$ & $(0.69,1.15,1.61)$ & $(0.36,0.50,0.64)$ & $(0.41,0.57,0.74)$ & $(0.034,0.047,0.061)$ \\
\hline
\end{tabular}

Step 4.3. Determination of the PIS and NIS.

Drawing on Equations (19) and (20), the PIS and NIS are acquired as follows:

$$
\begin{aligned}
& I^{+}=\{(2.98,3.83,3.83),(1.41,1.97,2.53),(0.36,0.50,0.64),(0.57,0.74,0.74),(0.034,0.047,0.061)\} \\
& I^{-}=\{(0.25,0.25,0.74),(0.16,0.49,0.81),(0.07,0.21,0.36),(0.05,0.14,0.24),(0.007,0.007,0.02)\}
\end{aligned}
$$

Step 4.4. Calculation of the closeness degree. 
The closeness degrees $C_{i}$ can be computed by Equations (21)-(24), which are illustrated in Table 6.

Table 6. The closeness degrees of the designs.

\begin{tabular}{ccccc}
\hline Criterion & Design 1 & Design 2 & Design 3 & Design 4 \\
\hline$d_{i}^{+}$ & 9.179 & 10.715 & 6.327 & 12.462 \\
$d_{i}^{-}$ & 9.009 & 13.865 & 6.596 & 12.894 \\
$C_{i}$ & 0.495 & 0.564 & 0.510 & 0.509 \\
\hline
\end{tabular}

The closeness degrees of each design are calculated, and the ranking of the design possibility is determined as in Table 7.

Table 7. Ranking of the design possibility.

\begin{tabular}{ccc}
\hline Design Possibility & $C_{\boldsymbol{i}}$ & Rank \\
\hline Design 1 & 0.495 & 4 \\
Design 2 & 0.564 & 1 \\
Design 3 & 0.510 & 2 \\
Design 4 & 0.509 & 3 \\
\hline
\end{tabular}

For managers, the degree of self-confidence is lower than that of designers, so the three-scale self-confidence is extended to five-scale self-confidence to express the situation of lack of self-confidence, as shown in Figure 9. The linguistic term which means the confidence in evaluation is "weak" is assigned $(0,0,0.1667,0.3333)$ TpFN, "unlikely" is assigned $(0.1667,0.3333,0.5) \mathrm{TFN}$, "neutral" is assigned $(0.3333,0.5,0.6667) \mathrm{TFN}$, "likely" is assigned $(0.5,0.6667,0.8333) \mathrm{TFN}$, and "absolutely" is assigned $(0.6667,0.8333,1,1) \mathrm{TpFN}$ over the total range of $[0,1]$.

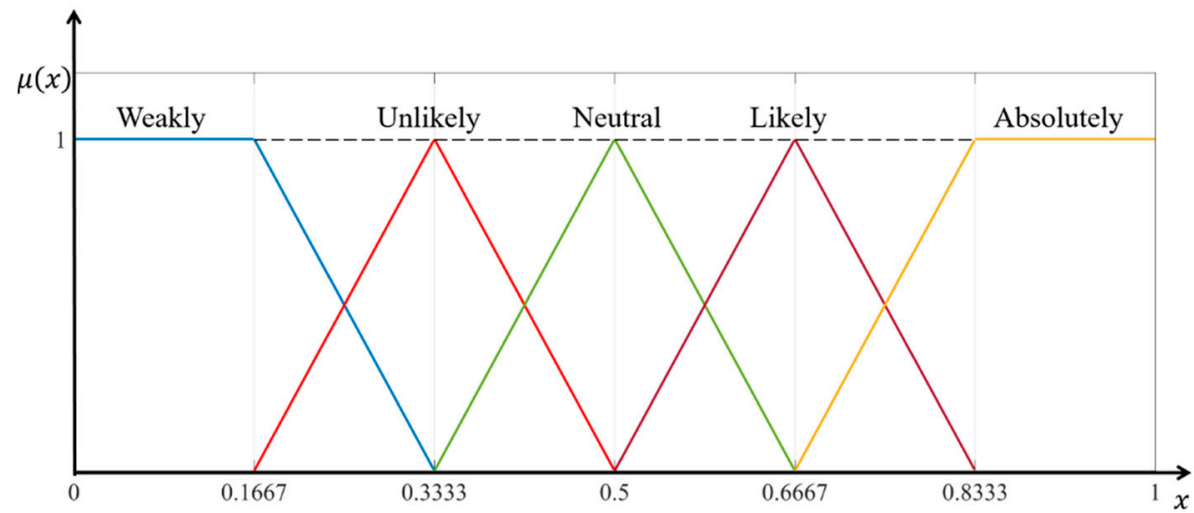

Figure 9. Five-scale self-confidence linguistic terms.

The Z-AHP pairwise comparison matrix and the Z-TOPSIS decision matrix of managers are shown in Tables 8 and 9. The closeness degrees and the ranking of the design possibility is determined as in Table 10.

Table 8. The fuzzy comparison matrix of managers for the criteria.

\begin{tabular}{cccccc}
\hline Criterion & $C_{\mathbf{1}}$ & $C_{\mathbf{2}}$ & $C_{\mathbf{3}}$ & $C_{\mathbf{4}}$ & $C_{\mathbf{5}}$ \\
\hline$C_{1}$ & $(1,1,1)$ & $(\mathrm{G}, \mathrm{L})$ & $(\mathrm{V}, \mathrm{U})$ & $(\mathrm{V}, \mathrm{L})$ & $(\mathrm{F}, \mathrm{W})$ \\
$C_{2}$ & - & $(1,1,1)$ & $(\mathrm{G}, \mathrm{N})$ & $(\mathrm{F}, \mathrm{A})$ & $(\mathrm{V}, \mathrm{L})$ \\
$C_{3}$ & - & - & $(1,1,1)$ & $(\mathrm{P}, \mathrm{N})$ & $(\mathrm{G}, \mathrm{L})$ \\
$C_{4}$ & - & - & - & $(1,1,1)$ & $(\mathrm{P}, \mathrm{L})$ \\
$C_{5}$ & - & - & - & - & $(1,1,1)$
\end{tabular}

P: Poor; F: Fair; G: Good; V: Very good; E: Excellent; W: Weak; U: Unlikely; N: Neutral; L: Likely; A: Absolutely. 
Table 9. Decision matrix of managers.

\begin{tabular}{cccccc}
\hline Criterion $\rightarrow$ & $C_{\mathbf{1}}$ & $\boldsymbol{C}_{\mathbf{2}}$ & $\boldsymbol{C}_{\mathbf{3}}$ & $\boldsymbol{C}_{\mathbf{4}}$ & $C_{5}$ \\
Alternative $\downarrow$ & $\boldsymbol{w}_{\mathbf{1}}=\mathbf{0 . 4 1}$ & $\boldsymbol{w}_{\mathbf{2}}=\mathbf{0 . 3 5}$ & $\boldsymbol{w}_{\mathbf{3}}=\mathbf{0 . 1 7}$ & $\boldsymbol{w}_{\mathbf{4}}=\mathbf{0 . 0 5}$ & $\boldsymbol{w}_{\mathbf{5}}=\mathbf{0 . 0 2}$ \\
\hline Design 1 & $(\mathrm{P}, \mathrm{W})$ & $(\mathrm{F}, \mathrm{N})$ & $(\mathrm{G}, \mathrm{A})$ & $(\mathrm{G}, \mathrm{A})$ & $(\mathrm{G}, \mathrm{A})$ \\
Design 2 & $(\mathrm{E}, \mathrm{A})$ & $(\mathrm{V}, \mathrm{A})$ & $(\mathrm{F}, \mathrm{A})$ & $(\mathrm{E}, \mathrm{A})$ & $(\mathrm{P}, \mathrm{A})$ \\
Design 3 & $(\mathrm{F}, \mathrm{W})$ & $(\mathrm{F}, \mathrm{W})$ & $(\mathrm{V}, \mathrm{N})$ & $(\mathrm{F}, \mathrm{W})$ & $(\mathrm{G}, \mathrm{W})$ \\
Design 4 & $(\mathrm{P}, \mathrm{N})$ & $(\mathrm{G}, \mathrm{N})$ & $(\mathrm{V}, \mathrm{A})$ & $(\mathrm{V}, \mathrm{A})$ & $(\mathrm{V}, \mathrm{A})$ \\
\hline
\end{tabular}

P: Poor; F: Fair; G: Good; V: Very good; E: Excellent; W: Weak; N: Neutral; A: Absolutely.

Table 10. Ranking of the design possibility (managers).

\begin{tabular}{ccc}
\hline Design Possibility & $\boldsymbol{C}_{\boldsymbol{i}}$ & Rank \\
\hline Design 1 & 0.5319 & 2 \\
Design 2 & 0.5449 & 1 \\
Design 3 & 0.5253 & 4 \\
Design 4 & 0.5316 & 3 \\
\hline
\end{tabular}

\section{Discussion}

It can be concluded from Table 7 that design 2 is the best scheme. Because designers are more confident in their evaluation, the closeness of design 2 is greater than that of the other three designs, which shows that if designers are more confident in evaluation, it is easier to get the best design, and the impact of confidence cannot be ignored. In Table 10, design 2 is also the best scheme, but because the managers are less confident than the designers, the closeness of the four schemes will be closer, so hesitation is not conducive to attaining the best scheme. It is worth noting that when hesitant, we can optimize design 2 through the confident content of other designs. For example, the convenience evaluation value of design 2 is good, and the confidence level is likely. In contrast, the convenience evaluation value of design 3 is very good, and the confidence level is absolutely. It is evident that design 3 is more convenient than design 2, so design 2 can be optimized by taking advantage of the advantages of design 3.

Design 3 adopts a side opening to improve convenience, so the side opening of design 3 is integrated into design 2, and then the original design is simplified and the runner at the bottom is removed to reduce complexity. The rendering of the final design is shown in Figure 10.

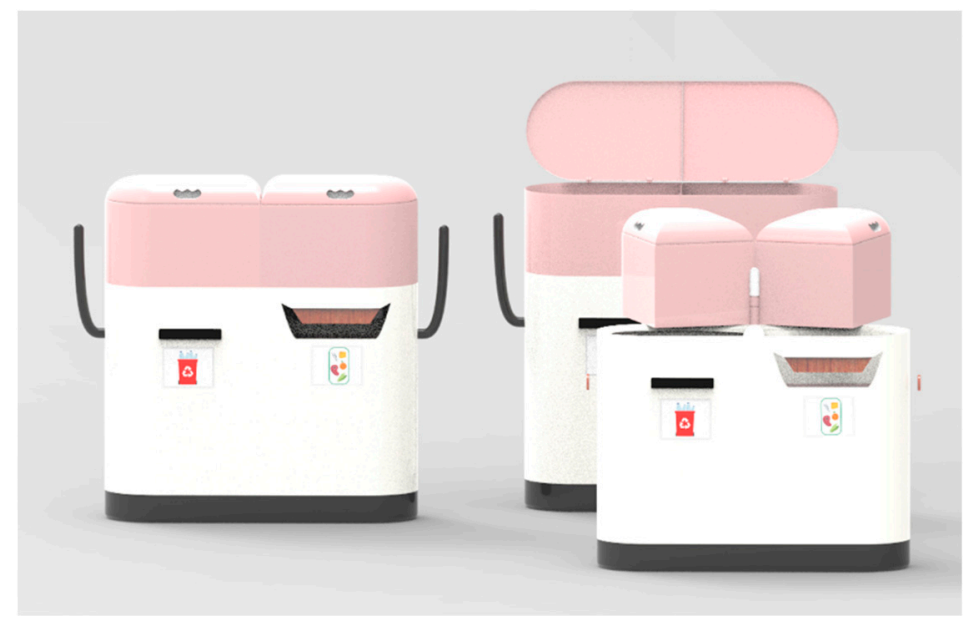

Figure 10. Final conceptual design.

As TOPSIS [44], fuzzy TOPSIS [45], AHP [46], and fuzzy AHP [47] do not consider the influence of self-confidence on the scheme, it can be seen from Table 10 that Design 3 = Design 4 when using these methods, because their evaluation values are the 
same, but the influence of self-confidence cannot be ignored, so Design $4>$ Design 3 in the actual situation. The same problem may occur when determining the weight of criteria.

In conceptual design evaluation, the hybrid fuzzy method is relatively safe $[39,48]$. Considering that with the increasing complexity of products more DMs may participate in the evaluation, ignoring the confidence may bring potential risks caused by their experience and knowledge differences.

According to the self-confidence, it is easier to determine the factors of customer needs and the advantages of the design. At the same time, it can improve the disadvantages of the design through other schemes. Therefore, in the conceptual design, the method proposed in this paper has more advantages than the method without considering the self-confidence.

\section{Conclusions}

Given the subjectivity and uncertainty in conceptual design evaluation, this paper proposes an evaluation method of different DMs using different evaluation confidence scales, which makes up for the deficiency of quantitative information reliability when using the fuzzy method.

In conceptual design evaluation, DMs evaluate the concept and indicate the degree of evaluation confidence. Z-number is used to represent the evaluation information of DMs, and it is transformed into a regular fuzzy number to express the fuzziness and reliability of the linguistic evaluation. The reliability of Z-numbers is used as the confidence level of DMs, making the decision more in line with the objective facts and providing more uses for the fuzzy linguistic quantification method. Therefore, a concept design evaluation method using DMs self-confidence is proposed. Different DMs can use different confidence scales to make practical decisions and avoid mistakes. In conceptual design evaluation, the evaluation framework of conceptual design based on customer requirements is constructed using the Z-AHP and Z-TOPSIS methods.

Finally, a design example is given to demonstrate the feasibility and superiority of the proposed method. The proposed method can reflect the opinions of DMs more comprehensively. With the subdivision of DMs' confidence level and confidence scale, a more reasonable and accurate ranking of design schemes can be obtained.

The proposed conceptual design evaluation framework can be integrated into many different stages of the product development process, such as customer participation evaluation. In this process, the use of confidence can better reflect the design problems. With the complexity of the product, the evaluation index will increase, which may exhibit the phenomenon of index coupling. In the future, we need to consider adding a correlation between the indexes to obtain a more realistic and more effective product scheme evaluation.

Author Contributions: Q.L.: conceptualization, methodology, investigation, formal analysis, writing - original draft, writing - review and editing. J.C.: conceptualization, methodology, data curation, project administration, supervision, writing-review and editing, funding acquisition. W.W.: formal analysis, writing-review and editing, funding acquisition. Q.Q.: investigation, formal analysis, writing - review and editing. All authors have read and agreed to the published version of the manuscript.

Funding: This research was funded by Youth Science and Technology Talent Growth Project by the Department of Education of Guizhou Province, grant number KY [2017]106 and KY [2018]112, and by the Science and Technology Foundation of Guizhou Province ([2020]1Y262).

Conflicts of Interest: The authors declare no conflict of interest.

\section{References}

1. Wang, J. Ranking engineering design concepts using a fuzzy outranking preference model. Fuzzy Sets Syst. 2001, 119, 161-170. [CrossRef]

2. Yang, Q.; Kherbachi, S.; Hong, Y.S.; Shan, C. Identifying and managing coordination complexity in global product development project. Int. J. Project Manag. 2015, 33, 1464-1475. [CrossRef]

3. Akay, D.; Kulak, O.; Henson, B. Conceptual design evaluation using interval type-2 fuzzy information axiom. Comput. Ind. 2011, 62, 138-146. [CrossRef] 
4. Herrera, F.; Herrera-Viedma, E. Linguistic decision analysis: Steps for solving decision problems under linguistic information. Fuzzy Sets Syst. 2000, 115, 67-82. [CrossRef]

5. Ashkenasy, G.; Ghadiri, M.R. Boolean logic functions of a synthetic peptide network. J. Am. Chem. Soc. 2004, 126, 11140-11141. [CrossRef] [PubMed]

6. Zadeh, L.A. Fuzzy sets as a basis for a theory of possibility. Fuzzy Sets Syst. 1999, 100, 9-34. [CrossRef]

7. de Sáa, S.R.; Gil, M.Á.; González-Rodríguez, G.; López, M.T.; Lubiano, M.A. Fuzzy rating scale-based questionnaires and their statistical analysis. IEEE Trans. Fuzzy Syst. 2014, 23, 111-126. [CrossRef]

8. Zadeh, L.A. A note on Z-numbers. Inf. Sci. 2011, 181, 2923-2932. [CrossRef]

9. Smets, P. Imperfect Information: Imprecision and Uncertainty; Springer: Boston, MA, USA, 1997; pp. 225-254. [CrossRef]

10. Julià, E.; Tillig, F.; Ringsberg, J.W. Concept Design and Performance Evaluation of a Fossil-Free Operated Cargo Ship with Unlimited Range. Sustainability 2020, 12, 6609. [CrossRef]

11. Qi, J.; Hu, J.; Peng, Y.H. New design concept evaluation method involving customer preferences based on rough distance to redefined ideal solution. Comput. Ind. Eng. 2020, 147, 106677. [CrossRef]

12. Filip, D. Modern methods and tools to improve the production processes from small series and unique production. Acta Tech. 2018, 61, 4 .

13. Sharaf, H.K.; Ishak, M.R.; Sapuan, S.M.; Yidrisn, N. Conceptual design of the cross-arm for the application in the transmission towers by using TRIZ-morphological chart-ANP methods. J. Mater. Res. Technol. 2020, 9, 9182-9188. [CrossRef]

14. Geng, X.; Chu, X. A new importance-performance analysis approach for customer satisfaction evaluation supporting PSS design. Expert Syst. Appl. 2012, 39, 1492-1502. [CrossRef]

15. Prasad, S.; Khanduja, D.; Sharma, S.K. Integration of SWOT analysis with hybrid modified TOPSIS for the lean strategy evaluation. Proc. Inst. Mech. Eng. Part B J. Eng. Manuf. 2018, 232, 1295-1309. [CrossRef]

16. Rondini, A.; Bertoni, M.; Pezzotta, G. An IPA based method for PSS design concept assessment. Procedia CIRP 2017, 64, 277-282. [CrossRef]

17. Lu, M.T.; Hsu, C.C.; Liou, J.J.H.; Lo, H.W. A hybrid MCDM and sustainability-balanced scorecard model to establish sustainable performance evaluation for international airports. J. Air Transp. Manag. 2018, 71, 9-19. [CrossRef]

18. Sedghiyan, D.; Ashouri, A.; Maftouni, N.; Xiong, Q.; Rezaee, E.; Sadeghi, S. Prioritization of renewable energy resources in five climate zones in Iran using AHP, hybrid AHP-TOPSIS and AHP-SAW methods. Sustain. Energy Technol. Assess. 2021, $44,101045$. [CrossRef]

19. Wu, Y.; Wang, J.; Ji, S.; Song, Z. Renewable energy investment risk assessment for nations along China's Belt \& Road Initiative: An ANP-cloud model method. Energy 2020, 190, 116381. [CrossRef]

20. Abdel-Basset, M.; Mohamed, R. A novel plithogenic TOPSIS-CRITIC model for sustainable supply chain risk management. J. Clean. Prod. 2020, 247, 119586. [CrossRef]

21. Pamucar, D.; Deveci, M.; Canitez, F.; Lukovac, V. Selecting an airport ground access mode using novel fuzzy LBWA-WASPAS-H decision making model. Eng. Appl. Artif. Intell. 2020, 93, 103703. [CrossRef]

22. Lerede, D.; Pinto, G.; Saccone, M.; Bustreo, C.; Capozzoli, A.; Savoldi, L. Application of a Stochastic Multicriteria Acceptability Analysis to support decision-making within a macro-scale energy model: Case study of the electrification of the road European transport sector. Energy 2021, 236, 121444. [CrossRef]

23. Coco, G.; Lagravinese, R.; Resce, G. Beyond the weights: A multicriteria approach to evaluate inequality in education. J. Econ. Inequal. 2020, 18, 469-489. [CrossRef]

24. Jasiulewicz-Kaczmarek, M.; Żywica, P.; Gola, A. Fuzzy set theory driven maintenance sustainability performance assessment model: A multiple criteria approach. J. Intell. Manuf. 2021, 32, 1497-1515. [CrossRef]

25. Yan, L.; Tang, X.; Huang, L.; Chen, B. Adaptive mask generating algorithm based on the fuzzy set theory for the weighted least-squares phase unwrapping. Opt. Lasers Eng. 2021, 146, 106721. [CrossRef]

26. Shaverdi, M.; Ramezani, I.; Tahmasebi, R.; Rostamy, A.A.A. Combining fuzzy AHP and fuzzy TOPSIS with financial ratios to design a novel performance evaluation model. Int. J. Fuzzy Syst. 2016, 18, 248-262. [CrossRef]

27. Abdel-Baset, M.; Chang, V.; Gamal, A.; Smarandache, F. An integrated neutrosophic ANP and VIKOR method for achieving sustainable supplier selection: A case study in importing field. Comput. Ind. 2019, 106, 94-110. [CrossRef]

28. Goswami, M.; Daultani, Y.; De, A. Decision modeling and analysis in new product development considering supply chain uncertainties: A multi-functional expert based approach. Expert Syst. Appl. 2021, 166, 114016. [CrossRef]

29. Onari, M.A.; Yousefi, S.; Rezaee, M.J. Risk assessment in discrete production processes considering uncertainty and reliability: Z-number multi-stage fuzzy cognitive map with fuzzy learning algorithm. Artif. Intell. Rev. 2021, 54, 1349-1383. [CrossRef]

30. Ghahtarani, A. A new portfolio selection problem in bubble condition under uncertainty: Application of Z-number theory and fuzzy neural network. Expert Syst. Appl. 2021, 177, 114944. [CrossRef]

31. Shen, K.; Wang, J. Z-VIKOR method based on a new comprehensive weighted distance measure of Z-number and its application. IEEE Trans. Fuzzy Syst. 2018, 26, 3232-3245. [CrossRef]

32. Hendiani, S.; Bagherpour, M.; Mahmoudi, A.; Liao, H. Z-number based earned value management (ZEVM): A novel pragmatic contribution towards a possibilistic cost-duration assessment. Comput. Ind. Eng. 2020, 143, 106430. [CrossRef]

33. Wang, J.; Cao, Y.; Zhang, H. Multi-criteria decision-making method based on distance measure and Choquet integral for linguistic Z-numbers. Cognit. Comput. 2017, 9, 827-842. [CrossRef] 
34. Peng, H.; Wang, J. Hesitant uncertain linguistic Z-numbers and their application in multi-criteria group decision-making problems. Int. J. Fuzzy Syst. 2017, 19, 1300-1316. [CrossRef]

35. Ren, Z.; Liao, H.; Liu, Y. Generalized Z-numbers with hesitant fuzzy linguistic information and its application to medicine selection for the patients with mild symptoms of the COVID-19. Comput. Ind. Eng. 2020, 145, 106517. [CrossRef]

36. Aydoğan, S.; Günay, E.E.; Akay, D.; Kremer, G.E.O. Concept design evaluation by using Z-axiomatic design. Comput. Ind. 2020, 122, 103278. [CrossRef]

37. Liu, Y.; Eckert, C.M.; Earl, C. A review of fuzzy AHP methods for decision-making with subjective judgements. Expert Syst. Appl. 2020, 161, 113738. [CrossRef]

38. Vinogradova-Zinkevič, I.; Podvezko, V.; Zavadskas, E.K. Comparative Assessment of the Stability of AHP and FAHP Methods. Symmetry 2021, 13, 479. [CrossRef]

39. Chang, D.Y. Applications of the extent analysis method on fuzzy AHP. Eur. J. Oper. Res. 1996, 95, 649-655. [CrossRef]

40. Shih, H.S.; Shyur, H.J.; Lee, E.S. An Extension of TOPSIS for Group Decision Making. Math. Comput. Model. $2007,45,801-813$. [CrossRef]

41. Akay, D.; Duran, B.U.; Duran, E.; Henson, B.; Boran, F.E. Developing a Labeled Affective Magnitude scale and Fuzzy Linguistic scale for tactile feeling. Hum. Factors Ergon. Manuf. Serv. Ind. 2021, 31, 13-26. [CrossRef]

42. Brouwer, R.K. Fuzzy set covering of a set of ordinal attributes without parameter sharing. Fuzzy Sets Syst. 2006, 157, 1775-1786. [CrossRef]

43. Kumar, P.; Tandon, P. A paradigm for customer-driven product design approach using extended axiomatic design. J. Intell. Manuf. 2019, 30, 589-603. [CrossRef]

44. Zhang, C.; Zhang, C.; Zhuang, J.; Han, H.; Yuan, B.; Liu, J.; Yang, K.; Zhuang, S.; Li, R. Evaluation of Cloud 3D Printing Order Task Execution Based on the AHP-TOPSIS Optimal Set Algorithm and the Baldwin Effect. Micromachines 2021, 12, 801. [CrossRef] [PubMed]

45. Roszkowska, E.; Kusterka-Jefmańska, M.; Jefmański, B. Intuitionistic Fuzzy TOPSIS as a Method for Assessing Socioeconomic Phenomena on the Basis of Survey Data. Entropy 2021, 23, 563. [CrossRef] [PubMed]

46. Alkharabsheh, A.; Duleba, S. Public Transportation Service Quality Evaluation during the COVID-19 Pandemic in Amman City Using Integrated Approach Fuzzy AHP-Kendall Model. Vehicles 2021, 3, 330-340. [CrossRef]

47. Li, Z.; Li, X.; Dong, C.; Guo, F.; Zhang, F.; Zhang, Q. Quantitative Analysis of Global Terrorist Attacks Based on the Global Terrorism Database. Sustainability 2021, 13, 7598. [CrossRef]

48. Azam, T.; Wang, S.; Mohsin, M.; Nazam, M.; Hashim, M.; Baig, S.A.; Zia-ur-Rehman, M. Does Stakeholder Pressure Matters in Adopting Sustainable Supply Chain Initiatives? Insights from Agro-Based Processing Industry. Sustainability 2021, 13, 7278. [CrossRef] 